\title{
Dental materials science: Research, testing and standards
}

DOI:

10.1016/j.dental.2021.01.027

\section{Document Version}

Accepted author manuscript

Link to publication record in Manchester Research Explorer

\section{Citation for published version (APA):}

Schmalz, G., Watts, D. C., \& Darvell, B. W. (2021). Dental materials science: Research, testing and standards. Dental Materials, 37(3), 379-381. https://doi.org/10.1016/j.dental.2021.01.027

\section{Published in:}

Dental Materials

\section{Citing this paper}

Please note that where the full-text provided on Manchester Research Explorer is the Author Accepted Manuscript or Proof version this may differ from the final Published version. If citing, it is advised that you check and use the publisher's definitive version.

\section{General rights}

Copyright and moral rights for the publications made accessible in the Research Explorer are retained by the authors and/or other copyright owners and it is a condition of accessing publications that users recognise and abide by the legal requirements associated with these rights.

\section{Takedown policy}

If you believe that this document breaches copyright please refer to the University of Manchester's Takedown Procedures [http://man.ac.uk/04Y6Bo] or contact uml.scholarlycommunications@manchester.ac.uk providing relevant details, so we can investigate your claim.

\section{OPEN ACCESS}




\title{
Editorial
}

\section{Dental materials science: Research, testing and standards}

\author{
G.Schmalz ${ }^{\mathrm{ab}}$, D.C.Watts ${ }^{\mathrm{c}}$, B.W.Darvell ${ }^{\mathrm{d}}$ \\ a Department for Conservative Dentistry and Periodontology, University Hospital \\ Regensburg, Regensburg, Germany. \\ ${ }^{b}$ Department of Periodontology, University of Bern, Bern, Switzerland \\ ${ }^{c}$ School of Medical Sciences, Division of Dentistry, University of Manchester, UK \\ d Dental Materials Science, University of Birmingham, UK
}

Dental Materials 2021; 37(3): 379-381. https://doi.org/10.1016/j.dental.2021.01.027

In a recent editorial [1], the question of selecting the appropriate method for addressing a specific dental materials research topic was addressed. A criticism was expressed about authors who, in order to justify test selection in a research paper, simply and only refer to the fact that the test was described in an ISO standard; such use has been explicitly encouraged [2]. In considering the ramifications of this, it might be worthwhile to consider the terms 'research' and 'test' a bit more closely. According to the Encyclopedia Britannica [3] , science is any system of knowledge that is concerned with the physical world and its phenomena and that entails unbiased observations and systematic experimentation. In general, science involves a pursuit of knowledge covering general truths or the operations of fundamental laws. Research means careful or diligent search or studious inquiry, examination, investigation or experimentation aimed at the discovery and interpretation of facts. The term test is described (1) as a critical examination, observation, or evaluation or (2) as a procedure ... used to identify or characterize something. In the context of statistical examination of data, a 'test' is used to determine the probability of an outcome against a formal 'null hypothesis', and thus potentially to falsify it according to the Popperian principle [4], despite its difficulties (e.g. Ref. [5] ). Alternatively, the word 'test' applies to a physical embodiment, the use of an instrument, device or experimental set-up to obtain a characterizing value for some property, or to observe some behaviour or effect, but it is also more concretely used for the test method as such. Testing, in whichever sense, is an integral part of the research endeavour, and is a fundamental component of the scientific method. 
In the dental materials field, the term research may be used to describe a rather basic approach, e.g. to develop new chemistry, or discover new mechanisms of action. The term test may be used in the context of characterizing a dental material or product in direct comparison with others but also for comparison with some defined or threshold value of the tested property, and it is in this sense that international standards are frequently and properly being used. The prime intention of establishing such international standards (e.g. ISO standards) for products is to provide test methods for those products and thus ascertain fulfillment or not of related requirements, primarily for performance and safety "rather than on chemical and/or physical properties" with consideration toward clinical relevance to contribute to improved oral and general health [,,$\underline{7}]$. In the biological context, standards might not contain stringent (i.e. pass/fail) requirements, but the results of such standardized tests are intended to be used within a clinical risk assessment. In any case, the aim is to set criteria for products, which - when having successfully passed these procedures - can be regarded as safe for humans and for the environment, and fit for their intended purpose $[\underline{6}, 7]$. For a number of years now such standards have also been used to test compliance with legal regulations, especially in order to permit market access for new products. This means that society has granted great trust in such standards for the protection of people and the environment, which in return means a great responsibility for those who set up and draft them. Consequently, therefore, standards bodies strive to base standards on the best available evidence, and to develop test procedures which are optimized for discriminatory power, reproducibility and comparability for use all over the world within constraints such as of expense, time, equipment and expertise availability, yet still sufficient for purpose with confidence. Accordingly, these standards are based on and contain much valid and valuable information, often to avoid pitfalls in testing, and they guarantee a certain level of methodological quality because they have been validated for their specific purpose internationally.

This valuable resource can and should be used wisely, for example when a new material or a new application method has been developed. That is, such new materials and applications ought to be tested for comparison with established procedures or products on the market in order to inform the dental community, including dental practitioners, of the potential application. Here, international standards for laboratory or in vitro testing may indeed play a beneficial role, as has clearly been outlined []ㅡ. In such a specific context, researchers are therefore well advised to consult such standards, if they exist for that topic. This does not, of 
course, mean that such tests are automatically the prime choice in every case, nor that deviations from the standards are not possible or allowed. It is the overriding responsibility of a scientist to determine which approach is the best for the particular task, making sure that there are no protocol defects that would compromise interpretation. There is a distinction to be drawn between a compliance test designed to be sufficiently discriminatory, e.g. for safety or performance, where a cost-benefit analysis is implicit, and one designed to obtain basic information on a new material, product or procedure. Nevertheless, if available, the body of standards should be regarded as a repository for methods to be seriously considered and as a valuable source of information []ㅡ where, quite specifically, a comparison with established products or procedures is required. Precise, easy to follow protocols, taking into account potential variables, are given in these standards. Following such a protocol exactly provides a certain level of assurance about the data derived in that context.

Thus, it is well accepted and understood, especially by the drafters, that laboratory test methods as are described in such standards may have severe limitations, some of which have been alluded to in the literature [9]. But, this does not disqualify them per se from being used in the proper way and in the right circumstances (as outlined above). Of course, there is no such thing as the perfect test method - we are all using model-based approaches, even when testing clinically. However, in the discussion of the results of such usage, these limitations must be carefully documented, addressed in the analysis, and taken into consideration in framing conclusions. This discussion should then be the impetus for the refinement and improvement of those methods (as implied below). Indeed, such consideration beforehand is expected to be routine, and modifications of the protocol to avoid, minimize or mitigate those limitations is sound scientific method.

The rather basic oriented research domain is generally regarded as more sophisticated than what is often called "only testing". For example, to receive extramural or non-industry funding for such testing, just to compare dental products, is virtually impossible, as opposed to obtaining funding for the basic oriented research in the field. An often-heard argument is that this sort of product comparison should be performed (and thus paid for) by industry. Also, some consider testing simply to report the mechanical properties of materials, for example, as simplistic and not "real research". Furthermore, it is also sometimes difficult to find a platform (i.e., a peer-reviewed journal), which will accept a paper on such reportage, which may not be seen as advancing science. However, for the practical use of the products 
in dental practice, that is, to guide the dentist in selecting from the range of available products, such information may be of value, at least for the time that they are marketed and available. Both domains, the rather basic oriented research and product testing, are necessary, although it should be kept in mind that a clear demarcation between the two is not always possible. However, data from both domains should in some way be peer reviewed and publically available.

Indeed, it is clear that it would be proper for investment to be made in research which has the explicit goal of improving the methods used in standards. This could be towards improving the discriminatory power, reliability, validity of application, efficiency, economy of effort, and so on, but also with a view to refinement based on our evolving understanding of the behaviour of mechanical tests, for example, or of the chemical processes occurring in products. There are also topics for which standardization is considered to be important, yet the absence of published satisfactory test protocols, or the data on which they could be designed, suggests that such investigations, i.e. to design standards tests, would be great value. This is for instance true in biological contexts.

Accordingly, a wider appreciation of the nature of standards and standards test methods would be beneficial both to the dental materials science research community and to the drafters of those very standards. Communication between the two could be facilitated by the active involvement of bodies such as the Academy of Dental Materials and the International Association for Dental Research. This may have a carry-over for dental practice in general, of course, but given the high expectations that governments, through accreditation or licensing bodies, have for the role and practice of standardization, and the commitment of standards bodies such as ISO to meeting those expectations, it is plain that such appreciation and focused research will indeed serve the greater good and the well-being of patients. 


\section{References}

[1] B.W. Darvell. Editorial: Misuse of ISO standards in dental materials research Dent Mater, 36 (2020), pp. 1493-1494

[2] A. Della Bona. Use of standards in papers published in dental journals Braz Dent J, 23 (5) (2012), pp. 471-476

[3] Britannica Academic.

https://academic.eb.com/levels/collegiate/search/dictionary?query=science\&includeLevelThr $\mathrm{ee}=1$ \&page $=1$.

[4] K.R. Popper. Conjectures and refutations. (3rd ed.), Routledge \& Kegan Paul, London (1969)

[5] N. Maxwell

A critique of Popper's views on scientific method. Philos Sci, 39 (2) (1972), pp. 131-152

[6] International Organization for Standardization (ISO). Scopes - ISO/TC 106 Dentistry Subcommittees 1 and 2.

iso.org/files/live/sites/tc106/files/TC\%20106\%20and\%20SC\%20Scopes_2018-11-09.pdf.

[7] International Organization for Standardization (ISO). ISO/TC 106 Dentistry Strategic Business Plan.

https://isotc.iso.org/livelink/livelink/fetch/2000/2122/687806/customview.html?func=1l\&objI $\mathrm{d}=687806 \&$ objAction=browse\&sort $=$ name.

[8] A. Della Bona, W.T. Wozniak, D.C. Watts. International dental standards - order out of chaos? Dent Mater, 27 (7) (2011), pp. 619-621.

[9] P. Cesar, R. Hickel, J.R. Kelly, U. Lohbauer, D.C. Watts. ADM research guidance papers Dent Mater, 33 (9) (2017), p. 967. 